\title{
A Conversation with Adrian Krainer
}

\author{
INTERVIEWER: ANKe SPARMANN
}

Senior Editor, Nature Structural \& Molecular Biology

\begin{abstract}
Adrian Krainer is the St. Giles Foundation Professor at Cold Spring Harbor Laboratory.
\end{abstract}
\begin{abstract}
Anke Sparmann: You were awarded the 2019 Breakthrough Prize in Life Sciences together with Dr. Frank Bennett of Ionis Pharmaceuticals for the development of antisense oligonucleotide drugs to target RNA splicing and the incredible success story of SPINRAZA, the first drug approved for spinal muscular atrophy. Can you start by telling us about this devastating disease and the molecular mechanism underlying it that you discovered?
\end{abstract}

Dr. Krainer: SMA, or spinal muscular atrophy, is a motor neuron disease. It's very severe, and it mainly affects infants and young children. There are milder forms of the disease, with delayed onset, which affect older patients, including adults. Depending on the type of SMA, it leads to progressive muscle weakness and paralysis, and it can be lethal. It's inherited as an autosomal recessive, Mendelian kind of disorder. The disease was well-characterized, and the responsible gene was identified in 1995. Sometime later - 4 years or so - it became clear that a defect in splicing is related to the disease. We began to work on that because our interests in my lab have always been on RNA splicing - both the fundamental science and the relationship to disease.

There are two genes that are closely related. One is missing or defective in patients; the other gene functions as a kind of backup. It can express the correct protein, but in fairly low amounts due to the type of splicing that the transcript undergoes. So, we began to characterize that process. We weren't the ones who described this difference in splicing, but we were interested in that general problem. Between the two genes, there are very few nucleotide differences, but one in particular had been pointed out in the exon that is inefficiently spliced. So, we studied that problem: What is it about that nucleotide? What is normally being recognized in the transcript by various factors? We worked on that for a couple of years, and then we began to think about how to correct the splicing of the SMN2 [Survival of Motor Neurons 2] RNA in order to allow the gene to produce higher levels of functional protein.

Anke Sparmann: How does this drug that was eventually developed actually work? How does it correct the splicing?

Dr. Krainer: It's a kind of drug called an antisense oligonucleotide. Those come in different modalities or "flavors," if you will. They're synthetic short nucleic acids, single-stranded. They have chemical modifications, and they can be designed to destroy the target RNA. They will home in on an RNA through base-pairing interactions, so they can be very specific. If the chemistry is designed in such a way that the duplex is recognized by endogenous RNase $\mathrm{H}$ enzymes, then they destroy the RNA target.

In our case, we use a different type of oligonucleotide design that binds to the RNA target by the same sort of physical chemical interactions, but it doesn't lead to its destruction. Instead, it blocks the binding of RNA-binding proteins. If you place an oligonucleotide in the correct place, then you can block the binding of a protein that affects splicing in some way. In our case, we were looking to block the binding of a splicing repressor, so that the exon that's nearby can now be recognized more efficiently by the splicing machinery. Now splicing looks more like it does in the SMN1 gene, even though we're targeting the $S M N 2$ gene that is still present in patients. If you deliver the drug to the right cell types, the cell now knows how to allow this gene to express higher levels of functional protein. That's the molecular mechanism of action of the oligonucleotide.

Anke Sparmann: You were involved from the start figuring out how this works, but then also all the way through to actually drug development. What were the major challenges throughout that whole process?

Dr. Krainer: There were many. This started as a very basic science kind of effort, and we made mechanistic observations that inspired a way to try to correct the defect, and we went through successive modalities for doing that. We learned things along the way. The ultimately successful approach was a bit simpler than the way we had started. Importantly, we began to collaborate with Frank Bennett at Ionis Pharmaceuticals in 2004. We had a lot of discussions and decided to use a particular kind of chemistry and to go with the approach that I just described, which is to find oligonucleotides that will block the binding of a repressor.

We did that very systematically. There was a postdoc who joined the lab at that time, Yimin Hua, who did pretty much all the early work, the key preclinical experiments.

(C) 2019 Krainer. This article is distributed under the terms of the Creative Commons Attribution-NonCommercial License, which permits reuse and redistribution, except for commercial purposes, provided that the original author and source are credited. 
We did have a lot of advice from Ionis people who were doing real pharmacology, but initially we were doing biochemistry, then cell-based experiments. Later, we set up mouse models. This took quite a number of years.

I don't know how to define when exactly we started working on this. We can put the start date when I, and my trainees, began to work on splicing, which is much earlier. On SMA specifically, we began around 2000 or 2001, with the work of a postdoctoral fellow, Luca Cartegni. The antisense screen, as it ultimately was carried out, began in 2004. The SPINRAZA molecule had other names earlier, but we published it in 2008. As things were progressing quite well, particularly when we began to do mouse-model experiments and seeing pretty dramatic results in terms of splicing and protein and phenotype, Ionis got quite serious about undertaking the clinical development and picking among the many different oligonucleotides that were effective, to look for the one that would be most specific and had minimum toxicity at high doses, etc. That's a separate effort in pharmacology, for which they had a lot of experience.

The next step was clinical trials. Those were initially sponsored by Ionis. About a year later, Biogen teamed up with them. The clinical trials were done in a variety of clinical centers and hospitals in several different countries. The key trials - Phases I through III- took about 5 years, which I think all went pretty smoothly. It ended up taking a year less than had been planned, because the results along the way were very encouraging. It was possible to complete the trials so that the patients still remained as part of an open phase extension study, beyond the original clinical trial. There are still ongoing clinical trials, but the ones that were key for obtaining the approval of the drug took about 5 years.

Anke Sparmann: Not that long ago, thinking of RNA as a drug molecule was not really out there. What were the changes that made this possible?

Dr. Krainer: It's all gradual. Like every new modality, there's a concept, and then there's the problems and reducing it to practice. There are always stumbling blocks. Typically, delivery of a new type of drug is something that requires a lot of effort. We were lucky that by the time we started working on this there were already several years of experience with antisense oligonucleotide pharmacology. They had gone through many chemistries. There was clinical experience, not so much with splice modulation, but nevertheless with the related chemistries. A lot of that knowledge - maybe more than 20 years of accumulated knowledge - is what makes these types of things possible. Monoclonal antibodies went through something similar. There was a description and one could see right away the potential, but to turn those into a drug took many years. Now, it's much more routine.

Anke Sparmann: You're looking at other diseases to target. What are you moving onto?

Dr. Krainer: Part of the lab still continues to study the basic fundamental aspects of splicing mechanisms and regulation, because the way we approach the problem is all based on insights about the mechanism. In this case, we were targeting a splicing repressor binding site. A few years earlier, we didn't even know these molecules existed, so one first had to discover that and understand something about how they work. We continue the basics, but we're also pursuing projects in which we try to apply similar or related approaches-blocking splicing components or RNA-binding proteins - in order to change splicing, and also other RNA processing, such as nonsense-mediated mRNA decay. We're exploring several potential targets that could lead to therapeutics for various diseases.

Anke Sparmann: In this basic kind of research, what is the next thing that's going to happen in splicing?

Dr. Krainer: That's moving along on many different fronts. When I started in this field, we were just doing cell-free splicing. It was all biochemistry. I started working on the development of systems for that as a graduate student. There was a lot to do, a lot of biochemistry to identify components. Of course, other labs were using genetic approaches and model organisms. Nowadays, there are many more disciplines that are contributing to understanding the whole process: quantitative approaches, bioinformatics, genomics, transcriptomics. A lot of techniques have been invented since I started in this field, so there are always new ways to revisit an approach. There are many powerful cell biology approaches, as well.

One sees steady progress on many fronts. Every once in a while, there are breakthroughs, so things advance more rapidly. The structural biology approach has had a tremendous impact in recent years with cryo-EM [electron microscopy]. Seeing snapshots of spliceosomes in action felt like the field suddenly moved forward 10 or 20 years. One could appreciate details, some of which were already known, but now you could really see it in real time. It was no longer an indirect demonstration or hypothesis. There's a lot of work that needs to be done using newer approaches like that to get new insights.

I think there will be a lot of surprises, and all these things inform how you might do therapeutics development where splicing underlies the overall approach. There are efforts to develop small molecules. It's not our work, but developments in the field to also modulate splicing, and so we need to understand better how these molecules are actually doing that. What's the mechanism of action? How specific are they, and how applicable is that approach to other targets, other splicing events? Structural insights from the spliceosome can inform those efforts and vice versa.

Anke Sparmann: Are there any problems with off-target effects of these kinds of drugs?

Dr. Krainer: Any drug obviously has that. With antisense oligos, because they're based on base pairing, you obviously have to pick sequences that are not repetitive. SPINRAZA, in particular, binds to a sequence that's unique: It's only present in intron 7 of the $S M N$ genes 
and nowhere else in the genome, at least as a perfect match. This doesn't rule out the possibility that imperfect binding - weaker binding, presumably — with one or more mismatches could occur. The question is, just because it binds somewhere else doesn't mean that it's going to perturb splicing or some other process, but there is that possibility. One has to be very careful about looking for adverse effects of drugs. Obviously, that's part of the whole clinical drug development.
With small molecules, it's a completely different mechanism of action. We need to understand better the few examples that we currently know of and how they're actually eliciting the changes in splicing. We understand a limited number of off-target effects and they appear to be quite specific, but maybe that can be improved. If you move to a different target, is it going to be possible to have similar specificity? That's something that the field is going to learn in the next few years. 


\section{$\$_{\text {CSH\& }}^{\infty}$ Cold Spring Harbor Symposia SYMPOSIA on Quantitative Biology}

\section{A Conversation with Adrian Krainer}

Cold Spring Harb Symp Quant Biol published online March 13, 2020

Access the most recent version at doi:10.1101/sqb.2019.84.039461

$\mathbf{P}<\mathbf{P} \quad$ Published online March 13, 2020 in advance of the print journal.

Creative This article is distributed under the terms of the

Commons http://creativecommons.org/licenses/by-nc/4.0/, which permits reuse and

License redistribution, except for commercial purposes, provided that the original author and source are credited.

Email Alerting Receive free email alerts when new articles cite this article - sign up in Service the box at the top right corner of the article or click here.

Advance online articles have been peer reviewed and accepted for publication but have not yet appeared in the paper journal (edited, typeset versions may be posted when available prior to final publication). Advance online articles are citable and establish publication priority; they are indexed by PubMed from initial publication. Citations to Advance online articles must include the digital object identifier (DOIs) and date of initial publication.

To subscribe to Cold Spring Harbor Symposia on Quantitative Biology go to: http://symposium.cshlp.org/subscriptions 